Alan Kreidstein DDS, $†$ Martin R. Boorin DMD, $\dagger^{*}$ Paul Crespi DDS, † Philip Lebowitz MD,* Samuel Barst MD*

\title{
Delayed awakening from general anaesthesia in a patient with Hunter syndrome
}

\begin{abstract}
Hunter syndrome is one of a heterogeneous group of recessively inherited mucopolysaccharide storage diseases (MPS) with similar biochemical defects manifested by impairments in mucopolysaccharide catabolism with variable but progressive clinical courses. Abnormal accumulation and deposition of mucopolysaccharides in the tissues of several organs lead to numerous anatomical, musculoskeletal and neurological abnormalities which are known to complicate anaesthetic and airway management. Hunter syndrome has a wide variance of clinical phenotypes ranging from mild to severe. We present a patient having physical and neurological features consistent with a severe clinical presentation of Hunter syndrome (MPS, Type II). Following a seemingly uneventful intraoperative anaesthetic course including isoflurane, nitrous oxide and fentanyl $(0.93$ $\mu \mathrm{g} \cdot \mathrm{kg}^{-l}$ ), resumption of spontaneous ventilation and return to consciousness were delayed until intravenous naloxone $(200$

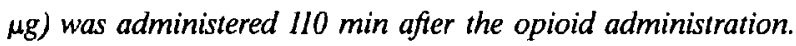
The cause of delayed recovery from anaesthesia in this patient is unknown.
\end{abstract}

La maladie de Hunter fait partie du groupe des affections hétérogènes héréditaires et récessives des mucopolysaccharidoses (MPS) avec lesquelles elle partage les mêmes anomalies biochimiques. Celles-ci se manifestent par des altérations du catabolisme des mucopolysaccharides et une évolution variable et progressive. L'accumulation anormale de mucopolysaccharides dans les tissus de plusieurs organes provoque de nombreuses lésions musculo-squelettiques et neurologiques qui com-

\section{Key words}

ANAESTHESIA: paediatric;

ANALGESICS: fentanyl;

SYNDROMES: mucopolysaccharidoses;

VENTILATION: anaesthetics, effects of.

From the Departments of Anesthesiology* and Dental Medicine†, Long Island Jewish Medical Center, New Hyde Park, New York 11042.

Address correspondence to: Dr. Martin R. Boorin, Department of Anesthesiology, Long Island Jewish Medical Center, New Hyde Park, New York 11042.

Accepted for publication Ist February, 1994. pliquent la gestion de l'anesthésie et des voies aériennes. Les phénotypes cliniques de la maladie de Hunter varient de légers à graves. Cette observation porte sur un patient qui présente des manifestations cliniques graves de la maladie de Hunter (MPS type II). A la suite d'une anesthésie sans problèmes réalisée avec de l'isoflurane, du protoxyde d'azote, et du fentanyl $\left(0,93 \mu \mathrm{g} \cdot \mathrm{kg}^{-1}\right)$, le retour normal à la ventilation spontanée et à la conscience est retardé jusqu'à l'administration de naloxone (200 mg) iv effectuée $110 \mathrm{~min}$ après le morphinique. La raison de ce retard est inconnue.

Hunter Syndrome (mucopolysaccharidosis, Type II) is one of the mucopolysaccharidoses (MPS), a rare group of recessively inherited connective tissue diseases characterized by a defect in the degradation of mucopolysaccharides normally present in connective tissues. Mucopolysaccharide accumulation involves multiple organs and tissues including bone, cartilage, brain, liver, spleen, blood vessels, skin, cornea, heart, and tracheobronchial airway structures. ${ }^{1,2}$ The clinical manifestations of Hunter syndrome, distinguished by $\mathrm{X}$-linked inheritance (incidence $1: 150,000)$, is due to an absence of the lysosomal enzyme iduronidate sulfatase resulting in visceral storage of dermatan sulfate and heparan sulfate, as well as increased urinary excretion of partially metabolized mucopolysaccharides. ${ }^{2-4}$ Although Hunter syndrome may occur in both severe and mild forms, it is distinguished from Hurler syndrome (MPS, Type I) by generally less severe mental retardation, joint disease and organ involvement as well as clear corneas, absence of gibbus, and a more gradual onset of the characteristic features. Retrospective clinical studies have estimated that airwayrelated problems occur in both the Hunter and Hurler syndromes in $50 \%$ of cases. ${ }^{5,6}$ Characteristics of Hunter syndrome typically become manifest by approximately two to four years of age, although the diagnosis of MPS Type II may now be made prenatally. 1,3 Abnormalities commonly include progressive mental retardation, hydrocephalus, neurological deterioration, ${ }^{2,5}$ growth retardation, macroephaly, coarse facies, skeletal abnormalities, stiff partial contracture of joints, hepato-splenomegaly, 
inguinal hernias, and progressive deafness. ${ }^{2}$ Occasionally, kyphosis, pectus carinatum or excavatum, congestive heart failure, and coronary artery occlusion may also occur. $2,3,7,8$

Children with Hunter syndrome commonly present with a variety of anatomic abnormalities of the face, oral cavity, and upper airway and frequently present with copious oral secretions, tongue protrusion and mouth breathing. The soft tissues of the mouth and lips are often turgid and can be manipulated only with difficulty. Other common findings include macroglossia, adenotonsillar hypertrophy, mucopolysaccharide deposition in the soft tissues of the upper airway, mucoid nasal discharge, acquired laryngotracheobronchomalacia and a short neck. ${ }^{8,9}$ The temporomandibular joints are stiff, and the larynx often appears to shift anteriorly and cephalad as further mucopolysaccharide is deposited with age in the upper airway. ' Hence, unaided visualization of the hypopharnyx and direct laryngoscopic visualization of the larynx are extremely difficult or impossible, which can have profound implications for the establishment and maintenance of an airway and represent the most frequently encountered anaesthesia-related problems in these patients. ${ }^{1,5,7,10}$

\section{Case report}

An eight-year-old, $27 \mathrm{~kg}$ boy with MPS, Type II, with a history of uncooperative behaviour for dental care, was scheduled for multiple dental restorations and extractions under general anaesthesia. Over the past two years the child's mental status had deteriorated leading to a nonverbal state; he was, however, able to follow simple commands. Major motor skills had also regressed and the child was no longer able to run or climb stairs. The family denied any history of respiratory problems or sleep apnoea. Preoperative physical examination revealed a dysmorphic child with shortened stature, mild kyphosis, systolic ejection murmur (felt by a paediatric cardiology consultation to be a benign flow murmur), generalized stiff joints, and hepatomegaly. Preoperative laboratory tests included an essentially normal haematological profile and urinalysis.

Head and neck findings included coarse and turgid facies, copious oral secretions, macroglossia, and macrocephaly, as well as restricted movement of the temporomandibular joints. The patient's short neck and infiltration of the subcutaneous structures of the head and neck contributed to severely restricted neck motion.

Past surgical history included: (1) bilateral myringotomies under general anaesthesia via mask and spontaneous respiration and (2) tonsillectomy, under inhalational general anaesthesia, two years prior to admission. Airway management during tonsillectomy, including tracheal in- tubation, was noted to have been difficult. Delayed emergence following the tonsillectomy had not been observed. In anticipation of a difficult airway, a fibreoptically assisted intubation was planned.

Prior to induction of anaesthesia, intravenous access was obtained. Following atropine, $0.3 \mathrm{mg} \dot{N}$, and preoxygenation, incremental doses of thiamylal (total dose 75 $\mathrm{mg} \dot{i}=2.8 \mathrm{mg} \cdot \mathrm{kg}^{-1}$ ) were administered to induce anaesthesia. An adequate airway was maintained with the aid of an oral airway, and the patient's anaesthesia level was deepened by assisted ventilation with $\mathrm{N}_{2} \mathrm{O}$ $(50 \%), \mathrm{O}_{2}(50 \%)$ and isoflurane. After a sufficient level of anaesthesia was obtained, laryngeal visualization using direct laryngoscopy was attempted but was complicated by non-compliant perioral tissues, reduced maximum inter-incisal distance and limited cervical extension. The initial laryngoscopic view was limited to the superior tip of the epiglottis. Despite apparent gentle handling of the tissues, bleeding from the gingival tissues developed making the subsequent fibreoptic intubation attempt difficult. After several attempts an oral endotracheal tube was successfully placed, without direct vision of the larynx, using a shoulder bolster and a straight Miller 2 blade.

Anaesthesia was maintained using $\mathrm{N}_{2} \mathrm{O} / \mathrm{O}_{2}$ and isoflurane (inspired concentration, $1.25 \%$ ) and supplemented by $i v$ administration of fentanyl $25 \mu \mathrm{g}\left(0.93 \mu \mathrm{g} \cdot \mathrm{kg}^{-1}\right)$. Controlled mechanical ventilation was initiated using intermittent positive pressure ventilation with peak airway pressures of $25-30 \mathrm{~cm} \mathrm{H}_{2} \mathrm{O}$ and an inspiratory-toexpiratory (I:E) ratio of 1:2. Minute ventilation was adjusted to maintain $\mathrm{PETCO}_{2}$ at $32-34 \mathrm{mmHg}$. The endtidal concentration of isoflurane was reduced to $0.5 \%$ by the end of the first hour of surgery and was subsequently reduced during the second hour of surgery to $0.2 \%$. Intraoperatively, oxyhaemoglobin saturation by pulse oximetry remained between 97 and $99 \%$, systemic blood pressure was $100-130 / 60-80 \mathrm{mmHg}$, while heart rate varied between 80 and $125 \mathrm{bpm}$. Difficult treatment access due to non-compliant perioral tissues led to considerable soft tissue retraction of the patient's lips, cheeks and enlarged tongue. Upon conclusion of the surgical procedure, the lips, soft palate and floor of the patient's mouth were noticeably swollen.

Isoflurane was discontinued ten minutes before the end of surgery and $85 \mathrm{~min}$ after the administration of the fentanyl bolus. Nitrous oxide was discontinued and the patient's lungs were ventilated with $100 \% \quad \mathrm{O}_{2} \quad(12$ $\left.\mathrm{L} \cdot \min ^{-1}\right)$. The patient's axillary temperature was $36.0^{\circ} \mathrm{C}$. Controlled patient ventilation continued for an additional ten minutes until $\mathrm{PETN}_{2} \mathrm{O}$ was undetectable with an end-tidal isoflurane concentration of $0.1 \%$. Nevertheless, the patient did not resume spontaneous respiration and assisted ventilation was maintained for an 
additional ten minutes. The $\mathrm{PETCO}_{2}$ was maintained at approximately $45 \mathrm{mmHg}$ until the end-tidal isoflurane concentration became undetectable. Over the next $15 \mathrm{~min}$ further attempts to allow restoration of spontaneous respiration failed. The patient was noted to have pin-point pupils and, because of the delayed emergence with a $\mathrm{PETCO}_{2}>55 \mathrm{mmHg}$, naloxone $(200 \mu \mathrm{g}) i v$ was administered. The patient immediately resumed spontaneous breathing, and the $\mathrm{PETCO}_{2}$ decreased promptly to 45-48 $\mathrm{mmHg}$ with a respiratory rate of $14-16 \mathrm{bpm}$. Tracheal extubation was performed in the operating room without complication. A nasopharyngeal airway was immediately inserted to avoid respiratory embarrassment secondary to surgically induced oral oedema.

Supplemental, humidified oxygen $\left(8 \mathrm{~L} \cdot \mathrm{min}^{-1}\right)$ was provided in the post-anaesthesia care unit (PACU). Vital signs on admission to the PACU were normal despite a respiratory rate of $8-10$ breaths $\cdot \mathrm{min}^{-1}$. However, the patient continued to require stimulation to maintain $\mathrm{SpO}_{2}$ $>93 \%$. Toward the end of the first hour, $\mathrm{SpO}_{2}$ gradually declined from $96 \%$ to $91 \%$ requiring administration of additional naloxone $(40 \mu \mathrm{g})$ iv which improved the patient's level of consciousness and eliminated further episodes of airway obstruction. $\mathrm{SpO}_{2}$ remained $>96 \%$ during the remainder of the patient's course in the PACU and the patient did not require additional analgesics while in the PACU. He was subsequently admitted to the hospital overnight for observation and $\mathrm{SpO}_{2}$ monitoring, no further episodes of oxyhaemoglobin desaturation or apnoea were noted and the patient was discharged the following morning after an uneventful overnight observation.

\section{Discussion}

In the case presented, our patient demonstrated respiratory depression (an increase in the $\mathrm{PaCO}_{2}$ apnoeic threshold) and decreased level of consciousness. These findings occurred approximately two hours after a single dose of fentanyl $\left(0.93 \mu \mathrm{g} \cdot \mathrm{kg}^{-1}\right)$ with a $\mathrm{PETCO}_{2}$ exceeding $55 \mathrm{mmHg}$ and in the absence of high enough concentrations of inhalational anaesthetics conventionally understood to delay awakening. Following naloxone, $200 \mu \mathrm{g}$ $i v$, rapid resumption of spontaneous respiration occurred, characterized by a respiratory rate of 14-16 breaths $\cdot \mathrm{min}^{-1}$ and tidal volumes of $150-200 \mathrm{ml}$. Over the next $40 \mathrm{~min}$, re-sedation of the patient was noted in the PACU resulting in partial airway obstruction, reduction of respiratory rate, and oxyhaemoglobin desaturation, which was promptly reversed by a second dose of naloxone, $40 \mu \mathrm{g} i v$.

Patients with Hunter syndrome have a reported perioperative complication rate of $50 \% .^{5,6}$ Young et al. reported serious problems associated with attempted intu- bation in 4/31 patients with the mild form of Hunter syndrome. Alterations in the upper and middle airways secondary to mucopolysaccharide tissue infiltration, in addition to frequent upper respiratory infections, limitation of TMJ movement, and macroglossia combine to make general anaesthesia hazardous in these patients. "Recovery from anaesthesia in patients with MPS is often slow. Although the aetiology of the problem is poorly defined, it may be complicated by episodes of apnoea, bronchospasm, cyanosis, and respiratory arrest. ${ }^{7,12}$ The postoperative course is likely to be stormy because of copious oral secretions, a rigid rib cage and pre-existing compromised cardiorespiratory function. "

Delayed awakening after general anaesthesia is a common problem. The aetiology can often be attributed to: (1) altered pharmacokinetic or pharmacodynamic profiles of anaesthetic drugs, (2) metabolic causes, or (3) neurologic injury. Prolonged sedation is most often related to the presence of residual general anaesthetic. Potent inhalational agents cause alveolar hypoventilation in a dose-dependent manner during spontaneous respiration and depressed ventilatory responses to hypoxia and hypercarbia. Elimination of volatile anaesthetics through the lungs may be prolonged in cases where minute ventilation has been reduced. Opioids produce a dose-dependent depression of the ventilatory response to $\mathrm{CO}_{2}$ by a direct effect on respiratory centres in the medulla. In patients with pre-existing pulmonary or CNS disease, severe respiratory depression and sedation may result from even analgesic doses. Similarly, intravenous sedation and anaesthetic agents produce dose-dependent respiratory depression as well as transient shifts of the $\mathrm{CO}_{2}$ response curve in the patient with chronic respiratory disease. Hypoxia and hypercarbia resulting from sedation, respiratory depression, and hypoventilation may directly potentiate the depressive effects of anaesthetics. ${ }^{13}$ Intraoperative monitoring of $\mathrm{SpO}_{2}$ and $\mathrm{PETCO}_{2}$ suggested that neither hypoxia nor hypercarbia were probable causes of our patient's delayed emergence.

The pharmacokinetic behaviour of low doses of fentanyl $\left(1-3 \mu \mathrm{g} \cdot \mathrm{kg}^{-1}\right)$ predicts a rapid redistribution of the drug to inactive tissue sites such as skeletal muscle and fat, with an associated decline in the plasma concentration leading to a short clinical effect independent of clearance rates. ${ }^{14}$ However, postoperative respiratory depression following general anaesthesia has been reported with lower fentanyl doses $\left(1-2 \mu \mathrm{g} \cdot \mathrm{kg}^{-1}\right){ }^{15}$ The lungs also serve as large, inactive storage sites with an estimated $75 \%$ of the initial dose of fentanyl undergoing first-pass pulmonary uptake. ${ }^{16}$ Elimination of fentanyl occurs predominantly by liver biotransformation but is limited by a large steady state volume of distribution ( $\mathrm{V}_{\text {Dss }}$ $=3.2-4.2 \mathrm{~L} \cdot \mathrm{kg}^{-1}$ ) and a long elimination half-life, 4-7 
hr. ${ }^{17}$ Hepatic dysfunction might have altered the clearance of fentanyl in this patient leading to delayed emergence despite a small total dose of opiate. Functional impairment of the liver has not been observed in MPS despite the high incidence of hepatomegaly. 1,3,9,11

Metabolic causes of delayed awakening, which include hypoglycaemia, hypocalcaemia, hyponantraemia and hypomagnesaemia, could not be demonstrated in this patient. In addition, hypothermia, advanced age, and renal disease may contribute to prolonged recovery from anaesthesia due to the increased sensitivity to or slowed elimination of administered medications (narcotics and benzodiazepines)..$^{13}$ None of these conditions was found in our patient. Likewise, neurological injury as a result of medullary compression, cerebrovascular accident, intracranial haemorrhage, paradoxical air emboli, fat emboli, and/or uncontrolled intraoperative hypotension could not be demonstrated.

We believe that this case report serves to highlight the problems of delayed recovery in patients with Hunter syndrome. While problems associated with the airway are the major complications associated with anaesthesia, this report suggests an increased sensitivity to anaesthetics. While unable to document increased sensitivity to fentanyl, we believe this to be the most likely cause of this patient's delayed awakening.

\section{References}

1 Sjogren, P, Pedersen T, Steinmetz H. Mucopolysaccharidoses and anaesthetic risks. Acta Anaesthesiol Scand 1987; 31: 214-8.

2 Smith DW. Recognizable Patterns of Human Malformation: Genetic, Embyronic, and Clinical Aspects. 3rd ed. Philadelphia: W.B. Saunders Company, 1982; 344-5.

3 Stanbury JB, Wyngaarden JB, Fredrickson DS. The metabolic basis of inherited disease. 5th ed. New York: McGraw-Hill, 1983; 47-9.

4 Katz J, Steward DJ. Anesthesia and Uncommon Pediatric Diseases. Philadelphia: W.B. Saunders Company, 1987, 354-6.

5 Herrick IA, Rhine EJ. The mucopolysaccharidoses and anesthesia: a report of clinical experience. Can J Anaesth 1988; 35: 67-73.

6 Baines $D$, Keneally J. Anaesthetic implications of the mucopolysaccharidoses: a fifteen-year experience in a children's hospital. Anaesth Intensive Care 1983; 11: 198-202.

7 King DH, Jones RM, Barnett MB. Anaesthetic considerations in the mucopolysaccharidoses. Anaesthesia 1984; 39: 126-31.

8 Gorlin RJ, Cohen MM Jr, Levin LS. Syndromes of the Head and Neck. 3rd ed. New York: Oxford University Press, 1990, 106-8.

9 Diaz $J H$, Belani KG. Perioperative management of chil- dren with mucopolysaccharidoses. Anesth Analg 1993; 77: 1261-70.

10 Kempthorne PM, Brown TCK. Anaesthesia and the mucopolysaccharidoses: a survey of techniques and problems. Anaesth Intensive Care 1983; 11: 203-7.

11 Young $I D$, Harper PS. Mild form of Hunter's syndrome: clinical delineation based on 31 cases. Arch Dis Child 1982; 57: 828-36.

12 Semenza GL, Pyeritz RE. Respiratory complications of mucopolysaccharide storage disorders. Medicine 1988; 67 ; 209-17.

13 Belatii RG Jr. Common post anesthetic problems. In: Vender JS, Spiess BD (Eds.). Post Anesthesia Care. Philadelphia: W.B. Saunders Company, 1992, 9-12.

14 Murphy MR, Olson WA, Hug CC Jr. Pharmacokinetics of ${ }^{3} \mathrm{H}$-fentanyl in the dog anesthetized with enflurane. Anesthesiology 1979; 50: 13-9.

15 Wood M. Opioid agonists and antagonists. In: Wood M, Wood A Jr (Eds.). Drugs and Anesthesia: Pharmacology for Anesthesiologists. Baltimore: Williams \& Wilkins, 1990, 150-1.

16 Stoelting RK. Pharmacology and Physiology in Anesthetic Practice. 2nd ed. New York: JB Lippincott, 1991, 85-8.

17 Roscow C. Pharmacology of Opioid analgetic agents. In: Rogers MC, Tinker JH, Covino BG, Longnecker DE (Eds.). Principles and Practice of Anesthesiology. St. Louis: Mosby Year Book, 1993, 1164-5. 